\title{
The process of fly ash magnetic separation impact on hydrothermal synthesis of zeolites
}

\author{
Natalia Czuma1,a, Katarzyna Zarębska1, Paweł Baran'1, Wojciech Franus² \\ ${ }^{1}$ AGH University of Science and Technology, Poland \\ ${ }^{2}$ Lublin University of Technology, Poland
}

\begin{abstract}
The aim of the experiment was modifying raw fly ash through the demagnetisation process and determining its influence on the efficiency of the synthesis of zeolite materials out of fly ash. A series of experiments have been performed on modified samples and, for the purpose of verification, on non-modified fly ash. No direct correlation has been confirmed in relation to synthesis efficiency as well as the type of obtained zeolite material. The research results indicate that the composition of fly ash determines the type of the zeolitic phases obtained. Based on the analysis of experimental data, it was found that the demagnetisation process allows to obtain additional zeolite phases, while there is no direct impact of the process used on the increase of synthesis reaction efficiency.
\end{abstract}

\section{Introduction}

Zeolites are crystalline aluminasilicates, formed by a continuous network of oxygen-sharing $\mathrm{AlO}_{4}$ and $\mathrm{SiO}_{4}$. They are characterized by a highly developed inner structure, which is responsible for very good sorption, catalytic and ion-exchange properties. Zeolites have regular and repeatable pores and channels with dimensions $0,4-0,15 \mathrm{~nm}$, which enable, among other things the separation of gas mixtures made out of components of different active molecule diameter [1]. Due to high industrial demand for zeolites, different methods of obtaining synthetic zeolitic materials have been developed. Zeolites synthesized out of fly ash are an attractive alternative for natural zeolites as well as for zeolites synthesized out of pure chemicals [2].

Currently the processes of zeolite synthesis can be divided mainly into: fusion method, hydrothermal synthesis and molten-salt method. In each variant it is possible to use the methods jointly and/or introduce modifications enhancing the synthesis process. Due to its functionality, the most widespread method of obtaining synthetic zeolitic materials out of fly ash is hydrothermal synthesis $[3,4]$. It is a complex physicochemical process, taking place in liquid phase in alkaline environment. Crystalline and amorphous substances which dissolve and crystallize are involved in the process [1]. The hydrothermal method with the use of fly ash makes it possible to obtain zeolitic materials type X, A and $\mathrm{P}[3,4$, 5].

According to recent literature on the subject $[1,6,7]$, the positive outcome of the synthesis is determined by the quality of fly ash, i.e. mainly the silica/alumina ratio, the selection of appropriate base solution and its amount, the synthesis conditions (temperature, time, pressure), the proportion of the solution used and the presence of additives.

One of the methods of fly ash modification discussed in literature is magnetic separation. The process is based on the removal of ferromagnetic minerals out of fly ash and its efficiency is determined by the intensity of the magnetic field used [1].

Magnetic separation-demagnetisation has been presented in literature as one of the methods of modifying fly ash before the synthesis, resulting in higher efficiency of the synthesis [8] or in the occurrence of new zeolite phases [9]. The aim of the process is to remove any ballast, which may have a negative influence on the formation of zeolites. Fly ash demagnetization can be performed with the use of the ,wet method" [10], without the use of liquid [11] or by a combination of both methods [11]. The use of acids in order to remove the metallic components is also possible [12].

For the purpose of examining the influence of the magnetic separation process, a series of hydrothermal synthesis were performed, aimed at receiving zeolite material out of non-modified fly ash from Polish Power plant (marked with symbol L in the work) as well as the same fly ash subjected to demagnetisation process (marked with symbol LO in the work). Due to its relative simplicity and low cost (no excessive energy penalty), the dry demagnetisation method was used in the experiment.

The synthesis was performed based on seven formulas differing in the concentration of the base solution, time and temperature of synthesis as well as in the use

\footnotetext{
a Corresponding author: nczuma@agh.edu.pl
} 
of synthesis enhancing additives. The aim of the experiment was to test whether the removal of ferromagnetic oxides will have a significant influence on the type of the zeolite material obtained and on the synthesis efficiency.

An additional advantage of the demagnetisation process is a potential possibility of industrial application of the residues from the demagnetisation process [10].

\section{Materials}

\subsection{Non-modified fly ash}

The fly ash marked L fly ash was used. The examined fly ash was characterized by $\mathrm{Si} / \mathrm{Al}=2,45$. The silica-alumina ratio in natural zeolites is approximately 1-6. From the value of $\mathrm{Si} / \mathrm{Al}$ in the fly ash used one can infer that the fly ash examined will be appropriate for the zeolite synthesis $[6,13,14]$.

The analysis of the XRF fly ash data before the modification made it possible to determine the qualitative and quantitative composition of fly ash: $\mathrm{Na}_{2} \mathrm{O}-2,3 \%, \quad \mathrm{MgO}-1,769 \%, \quad \mathrm{Al}_{2} \mathrm{O}_{3}-15,706 \%, \quad \mathrm{SiO}_{2}-$ $38,449 \%, \quad \mathrm{P}_{2} \mathrm{O}_{5}-0,743 \%, \quad \mathrm{SO}_{3}-1,038 \%, \quad \mathrm{~K}_{2} \mathrm{O}-2,773 \%$, $\mathrm{CaO}-3,578 \%, \quad \mathrm{TiO}_{2}-1,001 \%, \quad \mathrm{~V}_{2} \mathrm{O}_{5}-0,044 \%, \quad \mathrm{Cr}_{2} \mathrm{O}_{3}-$ $0,045 \%, \mathrm{MnO}-0,168 \%, \mathrm{Fe}_{2} \mathrm{O}_{3}-10,085 \%$, NiO-0,024\%, $\mathrm{CuO}-0,085 \%, \mathrm{ZnO}-0,987 \%, \mathrm{Ga}_{2} \mathrm{O}_{3}-0,006 \%, \mathrm{As}_{2} \mathrm{O}_{3}-$ $0,023 \%, \quad \mathrm{Rb}_{2} \mathrm{O}-0,014 \%$, SrO-0,047\%, $\mathrm{Y}_{2} \mathrm{O}_{3}-0,004 \%$, $\mathrm{ZrO}_{2}-0,03 \%, \quad \mathrm{Nb}_{2} \mathrm{O}_{5}-0,003 \%, \quad \mathrm{SnO}_{2}-0,022 \%, \quad \mathrm{BaO}-$ 0,094\%, PbO-0,298\%.

It was demonstrated that the fly ash contained the highest percentage of silicon and aluminum oxides along with a significant share of iron oxides, which prompted the decision to choose this fly ash for the research.

The mineral composition of a fly ash sample L was determined via powder X-ray diffraction. The XRD measurements (of both substrates and products) were carried out using PANalytical - Empyrean diffractometer, equipped with $\mathrm{Cu}-\mathrm{K} \alpha \quad(\lambda=1.5406 \AA)$ radiation source, within the $2 \theta$ range from $5-90^{\circ}$ and in a step size of $0.02 \% \mathrm{~min}$. XRD measurements were performed in temperature $25^{\circ} \mathrm{C}$. The diffractogram (Fig. 1) presents the fly ash sample L. It can be observed that the diffraction intensities characteristic for m-mullite, qquartz, Fe-magnetite and hematite are present.

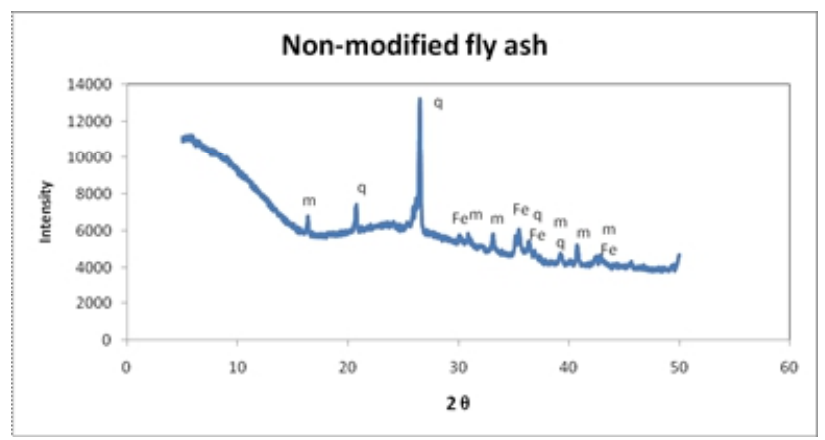

Figure 1. XRD diffractogram of non-modified fly ash
The iron oxides identified in fly ash in the form of magnetite and hematite derive mainly from the decomposition and oxidation during the combustion proces of the iron-bearing compounds from the coal (pyrite, siderite, ankerite, $\mathrm{Fe}^{2+}$-illite -clay mineral) [10].

Apart from magnetic components, the chemical composition of ferromagnetic compounds defined as ferrospheres is silica, alumina, calcium etc. [10]. These forms have a characteristic structure that may be recognised on SEM microphotographs.

In order to verify the presence of ferrospheres and attempt to identify them, SEM microphotographs of non-modified fly ash were taken (Fig. 2). The SEM microphotograph shows spherical forms characteristic of fly ash; additionally a number of amorphous forms can be observed which most probably originate from mullite, quartz and unburned carbon. In the center of the microphotograph, a spherical form with distinctive spots can be seen. It is assumed to be a ferrosphere with a smooth surface with ferromagnetic elements present.

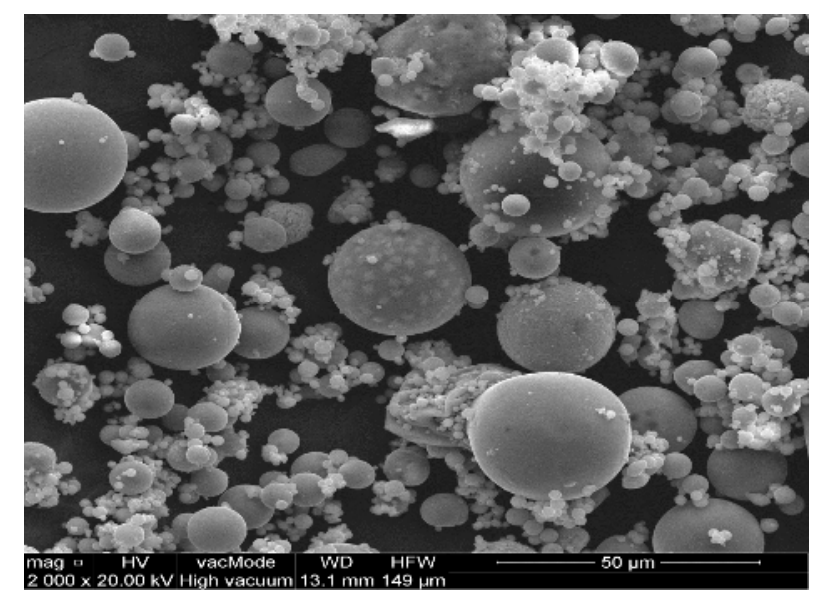

Figure 2. SEM microphotograph of non-modified fly ash

A further microphotograph analysis (Fig. 3) allowed to confirm the presence of spheres with a rough surface in the investigated material. By analogy to the ferrospheres described in literature, it is suspected that this stucture will probably be composed of magnetic elements.

In order to prove this hypothesis, the EDS analysis was performed.

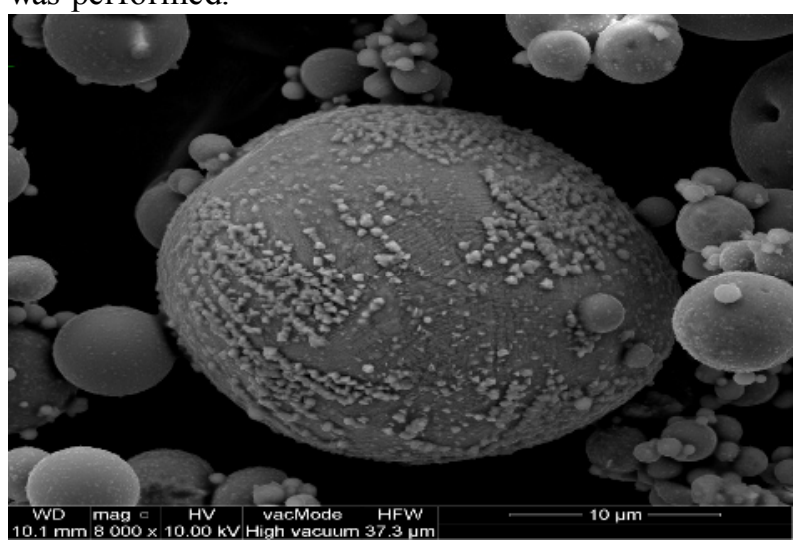

Figure 3. SEM microphotograph of ferrosphere, a fly ash particle 


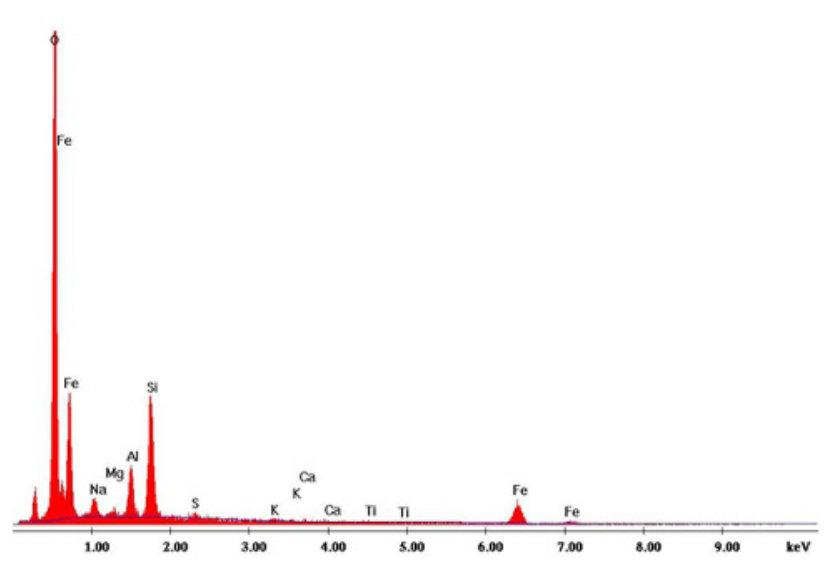

Figure 4. EDS spectrum of particle present in the Fig. 3

The analysis results presented in Fig. 4 reveal a significant iron content, which proves that the rough structure is a ferrosphere, composed mainly of iron, with silicon and aluminium

\subsection{Modified fly ash}

The process of the demagnetisation of fly ash was performed in a way presented schematically in Fig. 5.

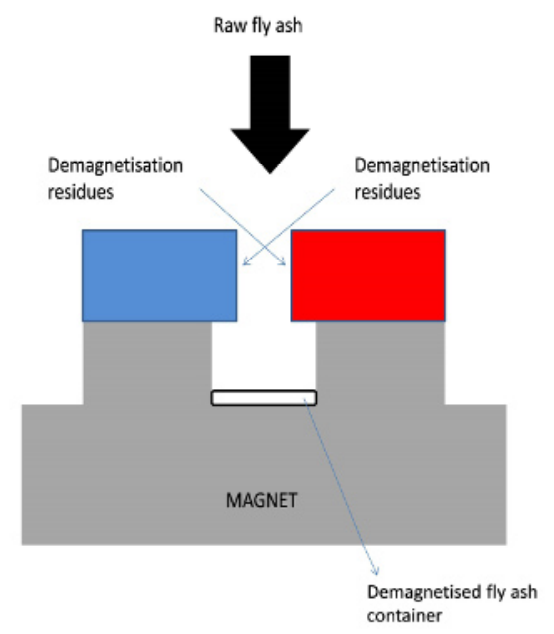

Figure 5. Scheme of the demagnetization process (own elaboration)

The magnetic separation process used in the experiment resulted in obtaining fly ash of the following composition: $\mathrm{Na}_{2} \mathrm{O}-2,141 \%, \mathrm{MgO}-1,7 \%$, $\mathrm{Al}_{2} \mathrm{O}_{3}-15,443 \%, \quad \mathrm{SiO}_{2}-38,651 \%, \quad \mathrm{P}_{2} \mathrm{O}_{5}-0,719 \%, \quad \mathrm{SO}_{3}-$ $1,35 \%, \mathrm{~K}_{2} \mathrm{O}-2,773 \%, \mathrm{CaO}-3,298 \%, \mathrm{TiO}_{2}-0,992 \%, \mathrm{~V}_{2} \mathrm{O}_{5}-$ $0,043 \%, \mathrm{Cr}_{2} \mathrm{O}_{3}-0,034 \%$, MnO-0,123\%, $\mathrm{Fe}_{2} \mathrm{O}_{3}-7,104 \%$, $\mathrm{NiO}-0,019 \%$, CuO-0,081\%, ZnO-0,97\%, BaO-0,071\%.

The diffraction patterns of modified (demagnetised) fly ash have been presented in Fig. 6. XRD data analysis, confirmed the presence of diffraction intensities characteristic for m-mullite and q-quartz.

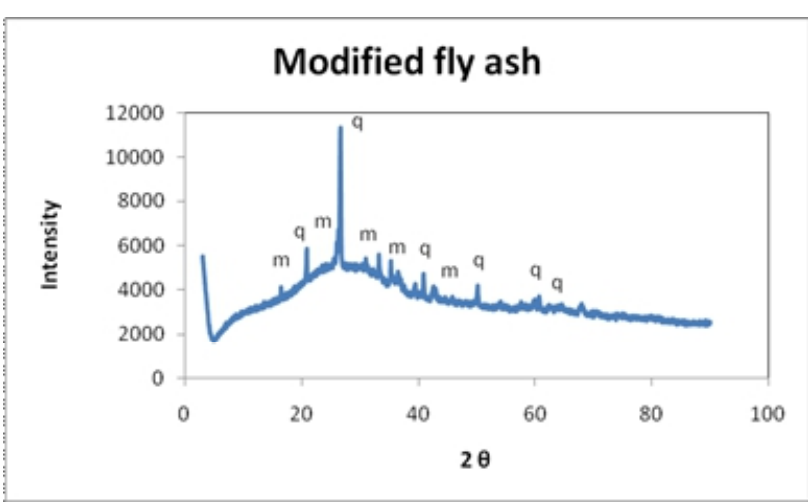

Figure 6. XRD diffractogram of modified fly ash-demagnetized

\subsection{Fly ash demagnetisation residues}

Additionally, the XRD analysis of residues from the demagnetisation process was performed, SEM microphotographs were taken and the EDS analysis carried out (Fig. 8, 9) . The diffractogram (Fig. 7) shows the peaks characteristic of m-magnetite and h-hematite.

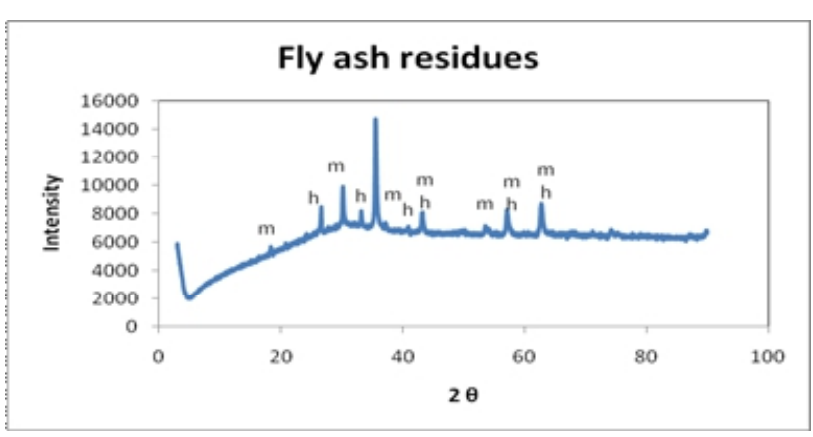

Figure 7. XRD diffractogram of magnetic residues after the demagnetisation of fly ash

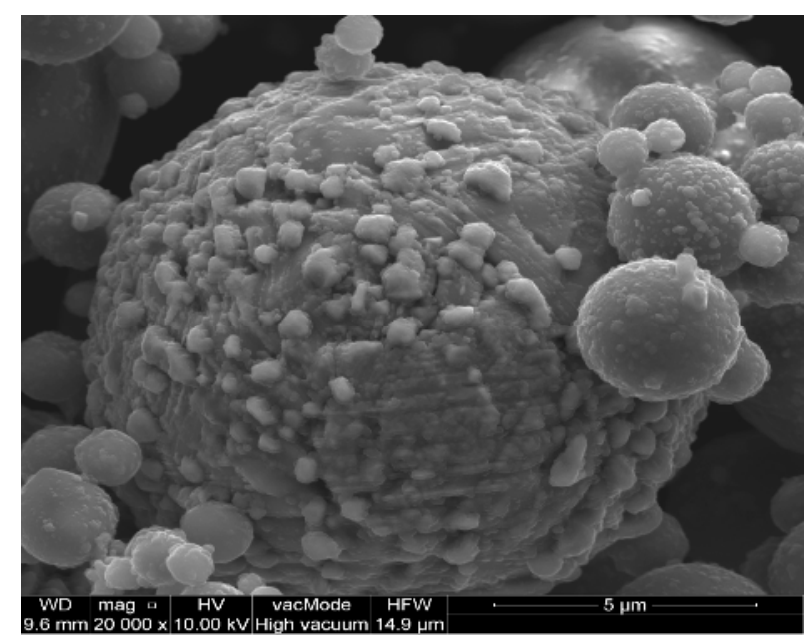

Figure 8. SEM microphotograph of magnetic residues after thedemagnetisation process

SEM-EDS data point taken at the centre of sphere presented in the Fig. 8, showed the predominant iron content in the chemical composition of the investigated point. 


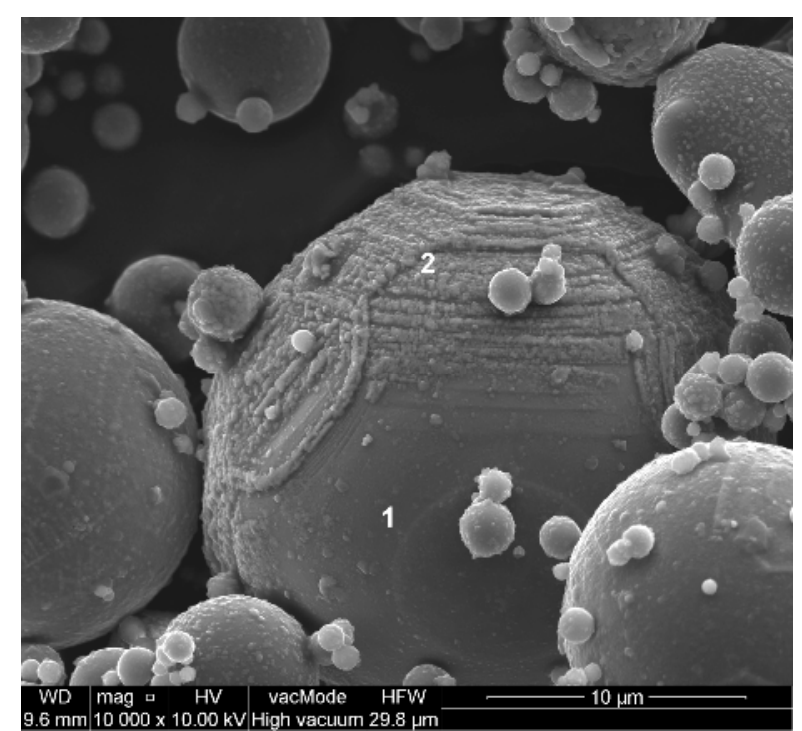

Figure 9. SEM microphotograph of magnetic residues after demagnetization process-microphotograph 2

An EDS analysis in point marked as 1 (Fig. 9) demonstrated the presence of iron and silicon, which proves that the sources of silicon are also being removed in the process of demagnetisation. The rougher surface in point marked as 2 is characterized by significant iron content.

In order to compare the impact of the modification process on the physical properties of fly ash, a helium density analysis was performed. The results have been presented in table 1 .

Table 1. Helium density of non-modified and modified fly ash

\begin{tabular}{|c|c|}
\hline & Density, $\mathrm{g} / \mathrm{cm}^{3}$ \\
\hline Non-modified fly ash & $\mathbf{2 , 3 2 1 1}$ \\
\hline Modified fly ash & $\mathbf{2 , 2 3 3 3}$ \\
\hline
\end{tabular}

The analysis of the helium density showed an expected decrease in the density of the fly ash subjected to modification, which was caused by the removal of higher-density material such as hematite, magnetite.

\section{Experimental}

For the purpose of the experiment, the hydrothermal synthesis method was adopted. It was performed on nonmodified and modified fly ash samples, using 7 different formulas for synthesis, in time ranges up to 24 hours, temperature from the range $80-105^{\circ} \mathrm{C}$ and base solution concentration of $1-5 \mathrm{~mol} / \mathrm{dm}^{3}$. The main synthesis parameters are presented in the table 2 .
As a result of the syntheses, light powders were obtained. The powders were rinsed up to $\mathrm{pH} \sim 10$, dried and analyzed with the XRD diffractometer in order to verify the effectiveness of the zeolite material synthesis and to estimate the influence of the demagnetization process on the zeolite phases obtained.The results of the synthesis performed have been presented in table 2 .

Table 2. Comparison of zeolitic products and synthesis parameters obtained in Methods 1-7 from syntheses based on non-modified and modified fly ash

\begin{tabular}{|c|c|c|c|c|c|c|}
\hline & 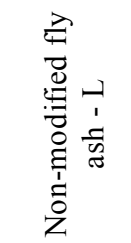 & 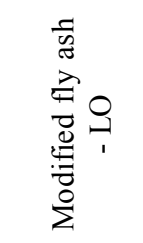 & 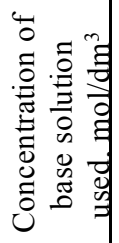 & 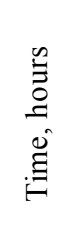 & 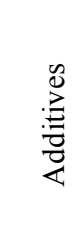 & 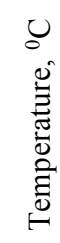 \\
\hline 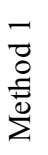 & $\mathrm{A}, \mathrm{P} 1$ & A,P1 & 2 & 24 & - & 80 \\
\hline 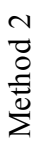 & A, X & A, X & 3 & 24 & - & 80 \\
\hline 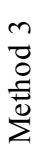 & $\mathrm{P} 1, \mathrm{~A}$ & $\begin{array}{c}\mathrm{X}, \\
\text { sodalite }\end{array}$ & 1 & 24 & $\mathrm{NaCl}$ & 80 \\
\hline 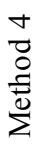 & sodalite & sodalite & 5 & 24 & $\mathrm{NaCl}$ & 105 \\
\hline 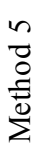 & $\begin{array}{c}\text { A, } \\
\text { chabazite }\end{array}$ & $\begin{array}{c}\text { A, } \\
\text { chabazite }\end{array}$ & 3 & 7 & $\mathrm{Al}$ & 95 \\
\hline $\begin{array}{l}0 \\
0 \\
0 \\
\stackrel{\Xi}{0} \\
\sum^{0}\end{array}$ & $\begin{array}{c}\text { A, } \\
\text { sodalite }\end{array}$ & A,sodalite & 1,5 & 7 & Al & 95 \\
\hline 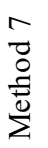 & $\mathrm{P} 1, \mathrm{X}$ & $\mathrm{P} 1, \mathrm{X}, \mathrm{A}$ & 2 & 22 & - & 95 \\
\hline
\end{tabular}

In table 3 the comparison of peak intensities from zeolite phases obtained from samples synthesised out of L and LO fly ash (estimated area under reflections), the aim of which was to compare the efficiency of the zeolite conversion process. 
Table 3. Comparison of the efficiency of the zeolitic products obtained in Methods 1-7 from syntheses based on non-modified and modified fly ash

\begin{tabular}{|c|c|c|}
\hline & $\begin{array}{c}\text { Non-modified fly ash } \\
- \text { L }\end{array}$ & Modified fly ash - LO \\
\hline Method 1 & higher efficiency & lower efficiency \\
\hline Method 2 & lower efficiency & higher efficiency \\
\hline Method 3 & \multicolumn{2}{|c|}{$\begin{array}{c}\text { different products received, no possibility of } \\
\text { efficiency comparison }\end{array}$} \\
\hline Method 4 & higher efficiency & lower efficiency \\
\hline Method 5 & higher efficiency & lower efficiency \\
\hline Method 6 & lower efficiency & higher efficiency \\
\hline Method 7 & higher efficiency & lower efficiency \\
\hline
\end{tabular}

\section{Results}

In the Fig. 10-16 diffraction patterns for each of the syntheses performed have been presented. The results of the syntheses made using non-modified fly ash and the one subjected to modification process were compared in order to identify the differences resulting from obtaining a different type of zeolite material.

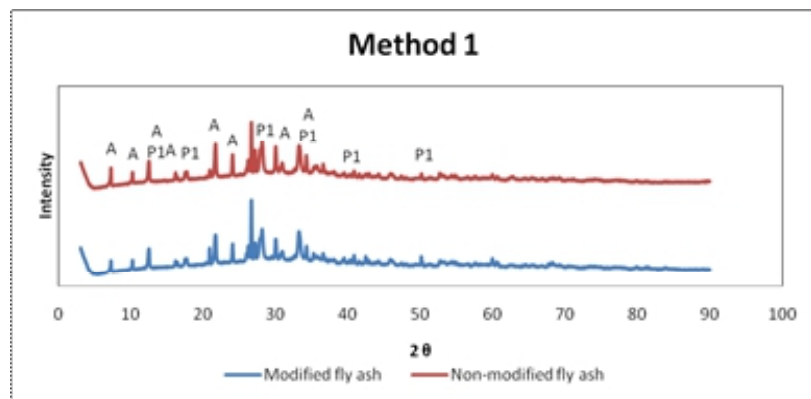

Figure 10. XRD diffractograms for synthesis products obtained using Method 1: red curve- the product of non-modified fly ash synthesis, blue curve- the product of modified fly ash synthesis (A-zeolite A, P1-zeolite P1)

In Method 1, based on a diffractogram analysis (Fig. 10) for the samples synthesised from non-modified and modified fly ash, it can be observed that some of the reflections overlap. For the reflections characteristic of zeolite phase A and P1, the ones from non-modified samples are more pronounced. By contrast, diffraction reflections of quartz are more significant for modified fly ash. Due to the lower conversion of quartz-Si source to the solution, lower diffraction intensities of zeolite phases are present in modified fly ash.

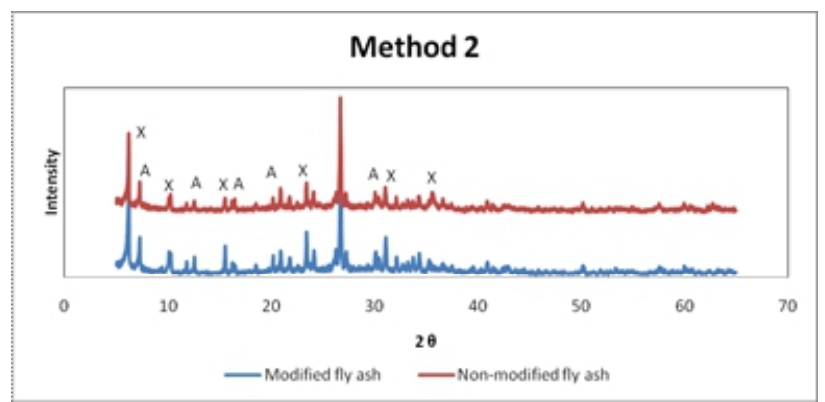

Figure 11. XRD diffractograms for synthesis products obtained from Method 2: red curve- the product of non-modified fly ash synthesis, blue curve- the product of modified fly ash synthesis (A-zeolite A, X-zeolite X)

Using Method 2, on the XRD diffractogram (Fig. 11), the overlaping of reflections were also observed, but there were differences in intensities. It is clearly visible that for a sample synthesised from modified fly ash, reflections of zeolite $\mathrm{A}$ and $\mathrm{X}$ are higher. The reflections characteristic of quartz are more intense for the sample synthesised from non-modified fly ash.

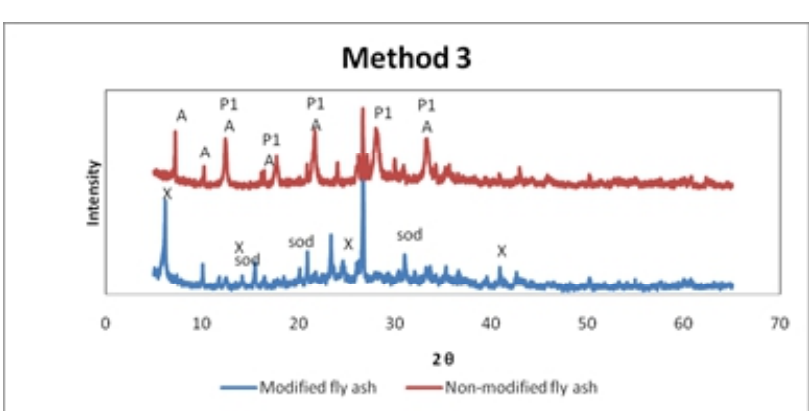

Figure 12. XRD diffractograms for synthesis products obtained from Method 3: red curve- the product of non-modified fly ash synthesis, blue curve-the product of modified fly ash synthesis (A-zeolite A, X-zeolite X, sod-sodlite)

In Method 3, based on the XRD diffractogram analysis (Fig. 12), it was found that reflections do not overlap. This proves the presence of other substances during the synthesis. For the sample synthesized from modified fly ash, the diffraction intensities characteristic of zeolite X of high intensity were present and those of sodalite. In the sample from non-modified fly ash the presence of zeolite A and P1 was confirmed. What is interesting is the presence of intensive peaks from quartz along with relatively high intensity peaks from zeolite $\mathrm{X}$.

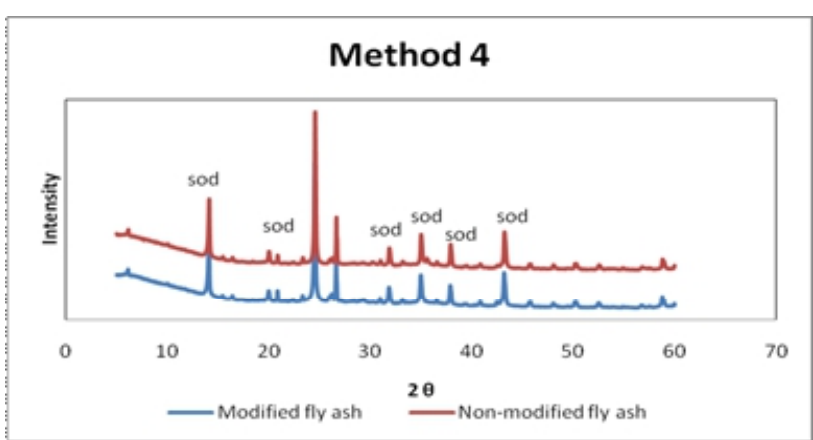

Figure 13. XRD diffractograms for synthesis products obtained from Method 4: red curve- the product of non-modified fly ash synthesis, blue curve-the product of modified fly ash synthesis (sod-sodalite)

Analyzing the synthesis results of Method 4 (Fig. 13), an overlap of diffraction intensities can be observed. The reflections from material synthesized from nonmodified fly ash are more pronounced than those from modified fly ash. It is worth noticing that in this synthesis the addition of $\mathrm{NaCl}$ was used. It may be assumed that the type of the crystallizing zeolite was determined by this additive. 


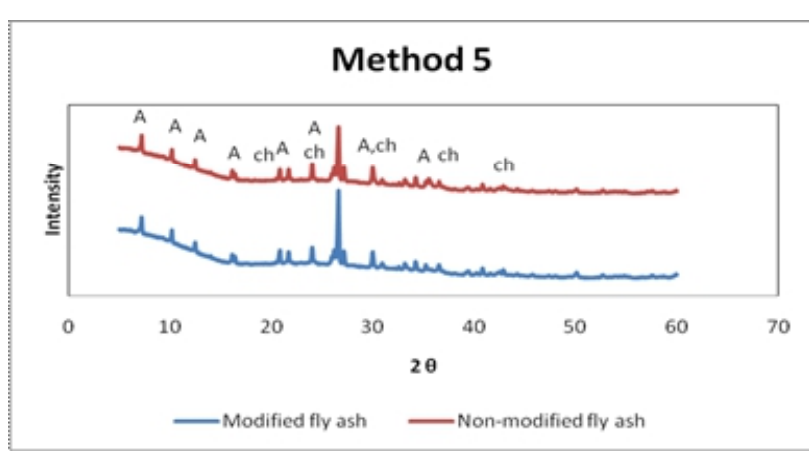

Figure 14. XRD diffractograms for synthesis products obtained from Method 5: red curve- the product of non-modified fly ash synthesis, blue curve-product of modified fly ash synthesis (Azeolite A, ch-chabazite)

In Method 5, based on XRD diffractogram analysis (Fig. 14) it can be observed that the reflections from the substance synthesized with the use of nonmodified fly ash overlap with most reflections from modified fly ash. The only reflections of higher intensity are representative of quartz.

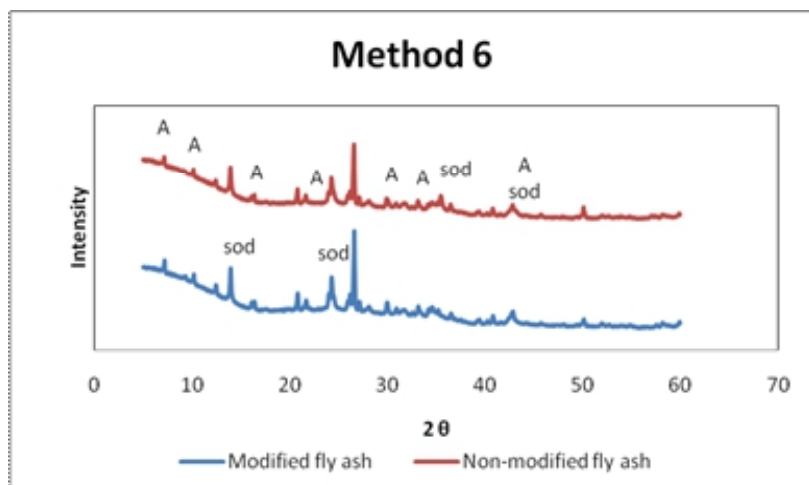

Figure 15. XRD diffractograms for synthesis products obtained from Method 6: red curve- the product of non-modified fly ash synthesis, the blue curve-product of modified fly ash synthesis (A-zeolite A, sod-sodalite)

Looking at the Method 6 XRD diffractograms (Fig. 15), a slight difference in reflections intensities may be observed. The modified fly ash peaks had higher intensity and in particular the zeolite A and quartz peaks are more intense.

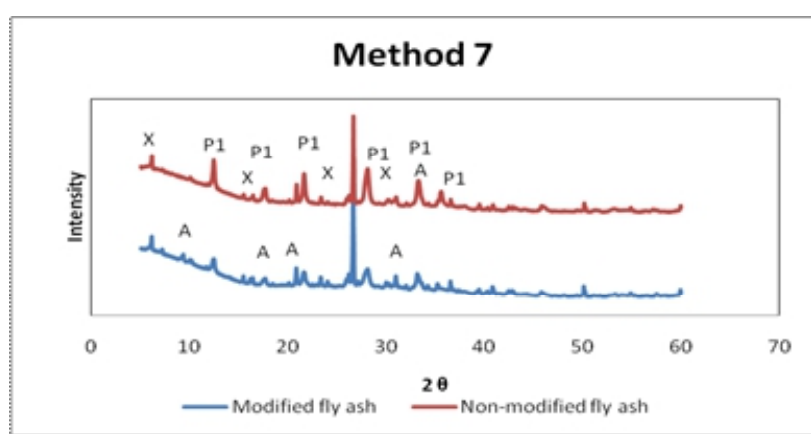

Figure 16. XRD diffractograms for synthesis products obtained from Method 7: red curve- the product of non-modified fly ash synthesis, blue curve-product of modified fly ash synthesis (Xzeolite X, A-zeolite A, P1-zeolite P1)

In Method 7 (Fig. 16), reflection intensities of peaks from zeolite phases are higher for samples synthesized from non-modified fly ash. For a sample from modified fly ash the presence of small reflections of zeolite A was noticed, which was not observed for the non-modified fly ash sample.

\section{Conclusions}

In theory, the demagnetisation of fly ash involving ballast removal should increase the efficiency of the zeolite synthesis from fly ash.

However, the results obtained in the research reveal that there is no direct correlation when it comes to the influence of the process of the fly ash demagnetisation on the synthesised material. The type of products obtained and the XRD diffraction intensities do not present a consistent pattern.

Only in one case (Method 3) different zeolite phases were identified, depending on the type of fly ash used for the synthesis.

It should be emphasised that in this method the base solution of the lowest concentration of $1 \mathrm{~mol} / \mathrm{dm}^{3}$ was used. In Method 7 the presence of a new zeolite phase was observed when a modified fly ash sample was used.

In the remaining examples the synthesis products differed in the diffraction intensities (the surface area under the most intensive peaks characteristic of a compound), which in approximation provides information about the quantity of the material obtained.

In Methods 5 and 6, it was noted that the addition of aluminum during the synthesis determined the crystallisation of a specific zeolite phase, i.e. zeolite $\mathrm{A}$, due to obtaining a $\mathrm{Si} / \mathrm{Al}$ ratio supporting the zeolite $\mathrm{A}$ synthesis. According to sources [7], the ratio $\mathrm{Si} / \mathrm{Al}$, should be in ranges 1-1,5 to favour zeolite A synthesis.

In the analysis of the syntheses results, it was helpful to identify zeolite phases as well as determine reflections intensities, understood as the surface area under the most intensive peaks characteristic of the given phase. Taking this criterion into account, in four samples (Method 1,4,5 and 7) higher reflection intensities from zeolite phases synthesised from non-modified fly ash were identified. In two samples (Method 2 and 6) on the other hand, higher reflection intensities were observed for modified fly ash samples.

In the syntheses performed, the only factor which had an impact on the type of the zeolite phase obtained was the fly ash demagnetisation process.

On the basis of the research conducted, a conclusion has been reached that in most cases the modification of raw fly ash through demagnetisation did not have the expected influence on the zeolite synthesis when it comes to the efficiency of the zeolite phase crystallisation.

It is not possible to draw a definitive conclusion whether the demagnetisation process of fly ash will impact the zeolite crystallisation process positively or negatively, depending on the synthesis parameters. Neither it is possible to determine if the demagnetised fly ash will increase or decrease the efficiency of the synthesis of the zeolitic material. However, since a new zeolite phase was obtained in one case when modified fly ash was used, it may be inferred that it is possible to obtain new zeolite phases providing that 
favourable parameters are used. The above analysis of the results obtained points to the necessity of conducting a parallel synthesis experiment on fly ash samples derived from a different power station.

\section{Acknowledgements}

The paper was financed from the AGH University of Science and Technology Statutory Research Fund no. 11.11.210.244.

\section{References}

1. T. Suchecki, Zeolity $\mathrm{z}$ popiołów lotnych. Otrzymywanie i aplikacje w inż. Środowiska, Ossolineum (2005)

2. B. Szala, P. Turek, A. Jeleń, T. Bajda, Inżynieria Środowiska, 150, 30 (2013)

3. W. Franus, M. Wdowin, M. Franus, Environ. Monit. Assess. 186, 9, 5721-5729 (2014)

4. M. Wdowin, M. Franus, R. Panek, L. Badura, W. Franus, Clean Technol. Envir. 16, 6, 12171223(2014)

5. X. Querol, J.C. Umaña, F. Plana, A. Alastuey, A. López-Soler, A. Medinaceli, A. Valero, M.J. Domingo, E. Garcia-Rojo, Fuel, 80, 857-865 (2001)

6. Wang Yanxin, Guo Yonglong, Yang Zhihua, Cai Hesheng, Xavier Querol, Sci China Ser D, 46, 9 (2003)

7. D. Sztekler, I. Majchrzak-Kucęba, W. Nowak, Monografia pod red. J. Ozonka, M. Pawłowskiej, 1, 58, 313-320 (2009)

8. R. Sommerville, R. Blissett, N. Rowson, S. Blackburn, Int $J$ Miner Process, 124, 20-25 (2013)

9. A.M. Cardoso, A. Paprocki , L.S. Ferret , C.M.N. Azevedo, M. Pires, Fuel, 84, 1351-1363 (2005)

10. Qing-feng Xue, Sheng-gao Lu, J Zhejiang Univ-Sc $A, \mathbf{9}, 11,1595-1600$ (2008)

11. A.G. Anshits, O.M. Sharonova, N.N. Anshits, S.N. Vereshchagin, E.V. Rabchevskii, L.A. Solovjev, World of Coal Ash (WOCA) Conference-May 9-12,2011, in Denver, CO, USA

12. K. Ojha, N.C Pradhan, A. N. Samanta, B Mater Sci, 27(6), 555-564 (2004)

13. Duangkamol Ruen-ngam, Doungmanee Rungsuk, Ronbanchob Apiratikul, Prasert Pavasant, Japca $J$ Air Waste Ma, 59, 10 (2009)

14. H.A. Ibrahima, A.M. El-Kamasha, M. Hanafyb, N.M. Abdel-Monemb, Chem Eng J, 144, 1, 67-74 (2008) 